\title{
Cytohistological Correlation of Palpable Breast Mass: A Study of 300 Cases
}

\author{
Aditi Dharmesh Vasavada ${ }^{1}$, Sheetal Kher ${ }^{2 *}$ \\ 'Dept of Pathology, Gotri Medical College, Vadodara, India \\ ${ }^{2}$ Dept of Pathology, GMERS Medical College Gotri, India
}

\begin{abstract}
Background: The present study is aimed at correlation of cytological and histological findings of palpable breast mass and evaluate efficacy of FNAC as a first line of investigation modality in breast lump.

Material Method: Total 378 female patients with breast lump were subjected to fine needle aspiration cytology examination and reported by using five tire system for breast cytology. Out of 378 cases, in 300 cases cytological findings were correlated with histological diagnosis.

Results: In present study, all benign, malignant and suspicious cases on cytology were well correlated with their histological diagnosis. The sensitivity, specificity and positive predictive value of FNAC for palpable breast lump are $97.7 \%, 98.8 \%$ and $97.7 \%$ respectively.

Conclusion: FNAC of breast lump is an effective, rapid, cost effective, though simple diagnostic procedure with excellent patient compliance. It is giving high accuracy rates when practiced by and experienced hand; making it one of the most reliable modality for evaluation of palpable breast mass.
\end{abstract}

Keywords: Breast Cytology, Five Tire System, Malignant Lesion.

\section{Introduction}

Palpable breast mass is the commonest presentation at surgical OPD. Breast malignancy is one of the commonest malignancy in women worldwide and its incidence increases with age. ${ }^{(1)}$ It is very essential to evaluate palpable breast mass before any surgical intervention. Most of the countries are now adopting "triple test" diagnostic approach for breast lesions i.e. clinical, radiological and pathological which include fine needle aspiration cytology as first line of investigation modality. ${ }^{(2)}$

FNAC carried out by a well trained, experienced hand, has high accuracy rate observed in many series. ${ }^{(3,4)}$ This makes it most reliable element of the triple test in cases where the three modalities are no concordant. ${ }^{(5,6)}$

Moreover, FNAC is a cost effective, simple diagnostic procedure for palpable breast lumps, ${ }^{(7)}$ which can be used on OPD basis without hospitalization of the patient. It is a minimally invasive procedure, less painful and having less chances of development of hematoma as compared to core needle biopsy. Patient compliance is best with this procedure even if it has to be repeated.

However, fine needle aspiration cytology can be presumptive in some cases. It is not a substitute of core needle biopsy. Final diagnosis can be obtained by histological examination of biopsy tissue. So present study is done to evaluate efficacy of FNAC in cases of palpable breast lesions, which is done by correlating cytological findings with histological diagnosis.

Aim of study: 1) To analyse various cytological findings of aspirates from palpable breast masses presented to cytology department and categorised them according to Five tire reporting system of breast cytology. 2) To correlate cytological diagnosis with histological examinations of breast lesions. 3) To evaluate sensitivity, specificity and predictive value of fine needle aspiration cytology in diagnosis of breast lesion.

\section{Materials and Methods}

The present study is performed in a tertiary health care centre in central Gujarat, from December 2014 to December 2016. During this period total 1560 patients referred from various outdoor patient departments were registered in cytology section of pathology department. Out of total 1560 patient, 378 female patients with palpable breast lesions were included in present study. Male patients with breast lump are not included in this study.

All the study participants were subjected to FNA examination after obtaining a written consent. The procedure of FNA was performed in supine position in a well lighted, properly ventilated room with maintaining privacy of the patients. The aspirations were taken using 23 
G needle attached to $10 \mathrm{ml}$ disposable syringe. The material obtained subsequently smeared on standard microscope glass slides, fixed with alcohol fixative and stained with $\mathrm{H} \& \mathrm{E}$ stain and modified Giemsa stain. A quick review of cellularity obtained in each aspiration was done on the spot immediately after staining the slides. The reporting of cytology slides was done using five tyre system for breast cytology. (table 1).

Out of these total 378 cases diagnosed cytologically, 300 cases subsequently subjected to histolopathological intervention. Cytological and histological diagnosis correlated in all the 300 cases. From the obtained data, statistical analysis was done.

\section{Result}

Data recorded from all the 378 female patients with palpable breast mass, entered in Microsoft Excel sheet. The age of the female patients in included in the present study ranged from 12 to 73 years. The age wise distribution of all the five categories ( $\mathrm{C} 1$ to $\mathrm{C} 5$ ) is shown in a bar diagram, which shows more than $50 \%$ patients with palpable breast mass falls in age range of 20 to 40years. This is the age range where maximum number of patients with palpable breast lesions are found. Total number of undiagnosed cases on FNAC was considered under $\mathrm{C} 1$ category which includes 32 cases in present study.

The bar diagram also shows maximum numbers of benign breast lesions (C2 category) havebeen found in age range of 20 to 30years. Commonest benign breast lesion found in present study wasfibroadenoma.

Maximum number of malignant breast lesions was found between $5^{\text {th }}$ and $6^{\text {th }}$ decade of life. All the six cases above 70 years of age were diagnosed malignant. Not a single benign case found in this age group. Maximum number of suspicious lesions (category $\mathrm{C} 3, \mathrm{C} 4$ ) were found between 35 to 50 years of age.

Out of total 378 cases of breast FNAC, histological correlation was available in 300 cases $(79.3 \%)$. Table 3 shows correlation between cytological and histological diagnosis of all the 300 cases in both malignant and benign categories. From the obtained data, sensitivity, specificity, positive predictive value, false negative rate and false positive rate for Breast cytology were calculated. (Table 4).

Table 1: Cytology categories according to five tire reporting system for breast cytology.

\begin{tabular}{|c|c|}
\hline Cytology categories & Explanation \\
\hline C1 & Inadequate \\
\hline C2 & Benign \\
\hline C3 & Suspicious but probably benign \\
\hline C4 & Suspicious but probably malignant \\
\hline C5 & Malignant \\
\hline
\end{tabular}

Table 2: shows age wise distribution of various pathological categories.

\begin{tabular}{|c|c|c|c|c|c|}
\hline & \multicolumn{5}{|c|}{ Cytology categories- according to Five Tire Reporting System } \\
\hline Age in years & $\mathbf{c 1}$ & $\mathbf{c 2}$ & $\mathbf{c 3}$ & $\mathbf{c 4}$ & $\mathbf{c 5}$ \\
\hline$<20$ & 8 & 38 & 1 & 1 & 3 \\
\hline $21-30$ & 10 & 81 & 6 & 2 & 2 \\
\hline $31-40$ & 6 & 47 & 8 & 6 & 16 \\
\hline $41-50$ & 8 & 24 & 3 & 8 & 22 \\
\hline $51-60$ & 5 & 4 & 4 & 4 & 35 \\
\hline $61-70$ & 2 & 6 & 2 & 1 & 9 \\
\hline$>70$ & 0 & 0 & 0 & 0 & 6 \\
\hline
\end{tabular}

Table 3: Cyto-Histological correlation of 300 cases of Breast lesions.

\begin{tabular}{|c|c|c|c|}
\hline Cytological categories* $^{*}$ & No. of patients & \multicolumn{2}{|c|}{ Histology diagnosis } \\
\hline C1 & & Benign & Malignant \\
\hline C2 & 32 & 31 & 01 \\
\hline C3 & 170 & 169 & 01 \\
\hline
\end{tabular}




\begin{tabular}{|c|c|c|c|}
\hline Cytological categories* $^{*}$ & No. of patients & \multicolumn{2}{|c|}{ Histology diagnosis } \\
\hline & & Benign & Malignant \\
\hline C4 & 10 & 02 & 78 \\
\hline C5 & 78 & 00 & 90 \\
\hline Total & 300 & 210 & 78 \\
\hline
\end{tabular}

*C1 for inadequate; C2 for benign; C3 forsuspicious, probably benign; C4 for suspicious, probablymalignant; and C5 for malignant breast lesions

Table 4: Statistical analysis of data obtained in present study.

\begin{tabular}{|c|c|c|c|}
\hline \multirow{2}{*}{ Cytological diagnosis } & \multicolumn{2}{|c|}{ Histological diagnosis } & \multirow{2}{*}{ Total no. Of cases } \\
\hline & Positive for malignancy & Negative for malignancy & \\
\hline Positive for malignancy $(\mathrm{C} 5+\mathrm{C} 4)^{*}$ & $\mathrm{TP}=86$ & $\mathrm{FP}=2$ & 88 \\
\hline Negative for malignancy $(\mathrm{C} 2+\mathrm{C} 3) \#$ & $\mathrm{FN}=2$ & $\mathrm{TN}=178$ & 180 \\
\hline Total no. Of cases diagnosed & 88 & 180 & 268 \\
\hline \multicolumn{4}{|c|}{ 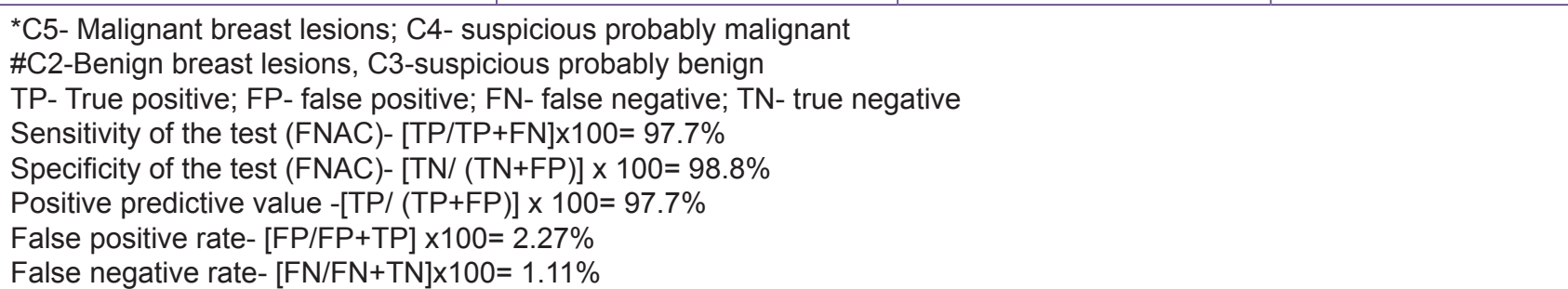 } \\
\hline
\end{tabular}

Table 5: Comparison of statistical results of present study with other studies:

\begin{tabular}{|l|c|c|c|c|}
\hline Parameter & $\begin{array}{c}\text { Results in present } \\
\text { study }\end{array}$ & Chavda J (2013) & $\begin{array}{c}\text { A.Daramola et al } \\
(\mathbf{2 0 1 5 )}\end{array}$ & $\begin{array}{c}\text { N.Chauhan et al } \\
\mathbf{( 2 0 1 2 )}\end{array}$ \\
\hline Sensitivity & $97.7 \%$ & $95.2 \%$ & $95.4 \%$ & $96.6 \%$ \\
\hline Specificity & $98.8 \%$ & $100 \%$ & $88.9 \%$ & $100 \%$ \\
\hline Positive predictive value & $97.7 \%$ & $100 \%$ & $99.6 \%$ & $100 \%$ \\
\hline False negative rate & $1.11 \%$ & $4.76 \%$ & $0.8 \%$ & $1.9 \%$ \\
\hline False positive rate & $2.27 \%$ & $0 \%$ & $0.4 \%$ & -- \\
\hline
\end{tabular}

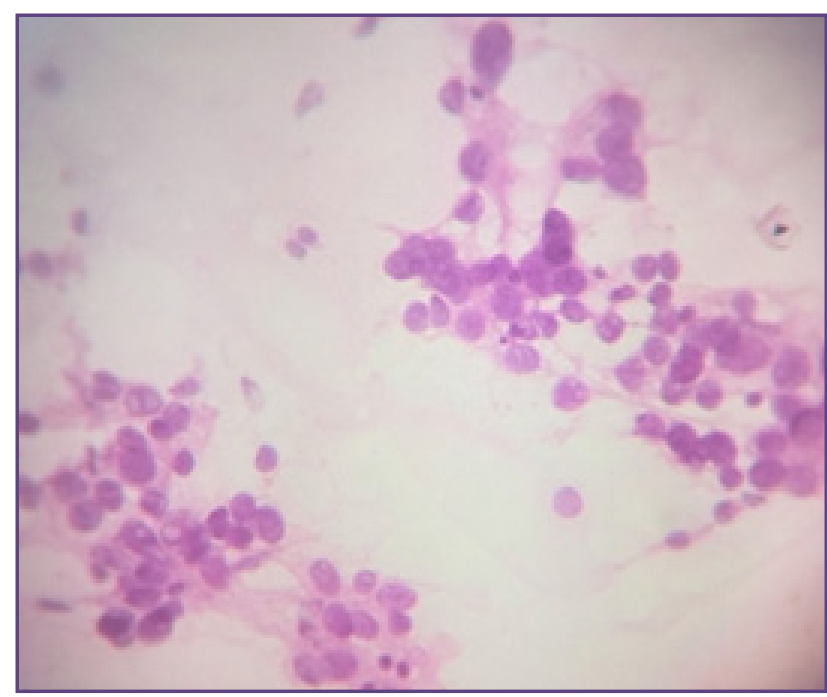

Fig. 1: cytology smear of Malignant breast lesion, showing loosely cohestive clusters of ductal epithelial cells with moderate anisonucleosis, H \& E stain, 400X.

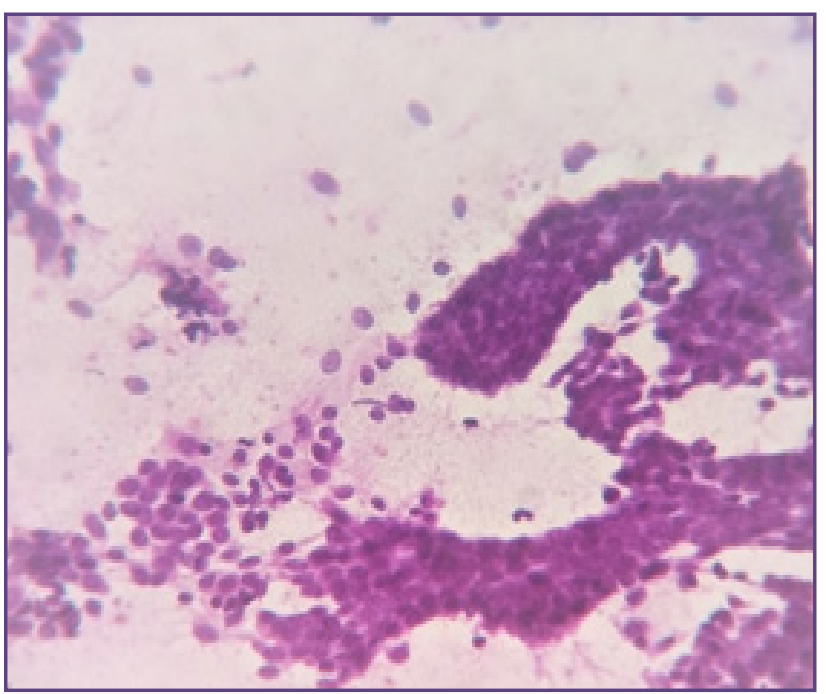

Fig. 2: Cytology smear- Benign Breast lesionFibroadenoma, Giemsa stain, 400X. 


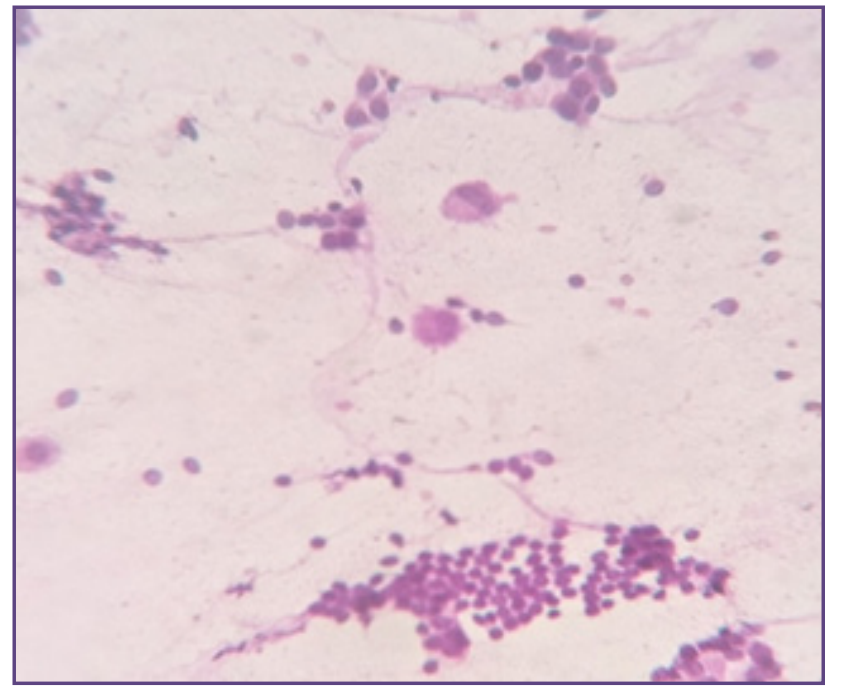

Fig. 3: Cytology smear- Benign proliferative breast lesionwith apocrine changes, $H \& E$ stain, 100X.

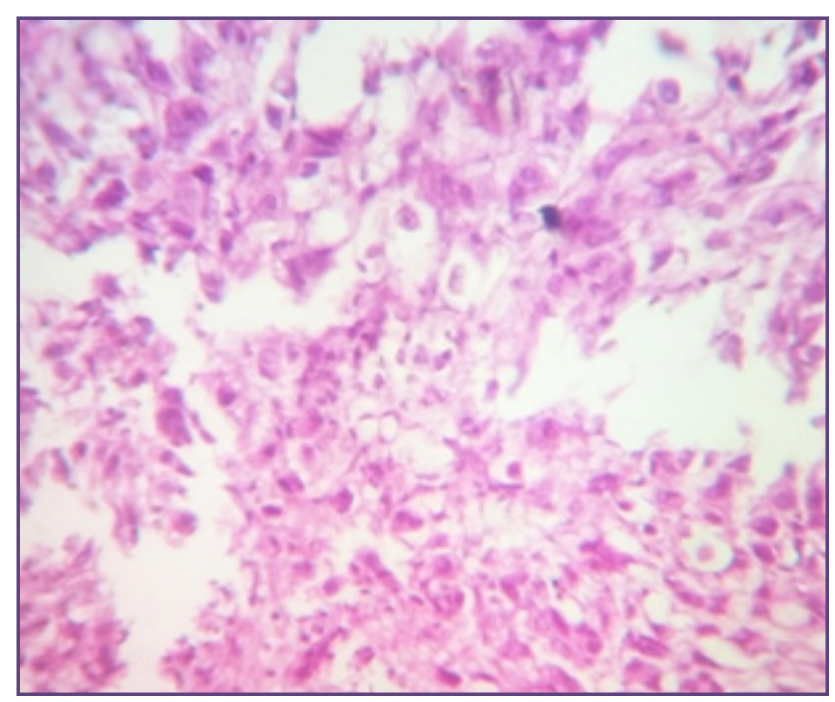

Fig. 5: Histology of Malignant breast lesion- Invasive Ductal Carcinoma, H \& E stain, 400x.

\section{Discussion}

FNAC of palpable breast masses is considered as a quick, inexpensive, painless and safe procedure. Also, it gives reliable results as far as early detection of breast cancer is considered. This technique is very well accepted by the patient even if it had to be repeated. The only complication arises that is development of hematoma; which can be very well prevented by applying gentle pressure over the site of procedure for short duration.

Most countries have now adopted triple assessment approach (clinical, radiological, and pathological) for palpable breast masses, with FNAC as the first-

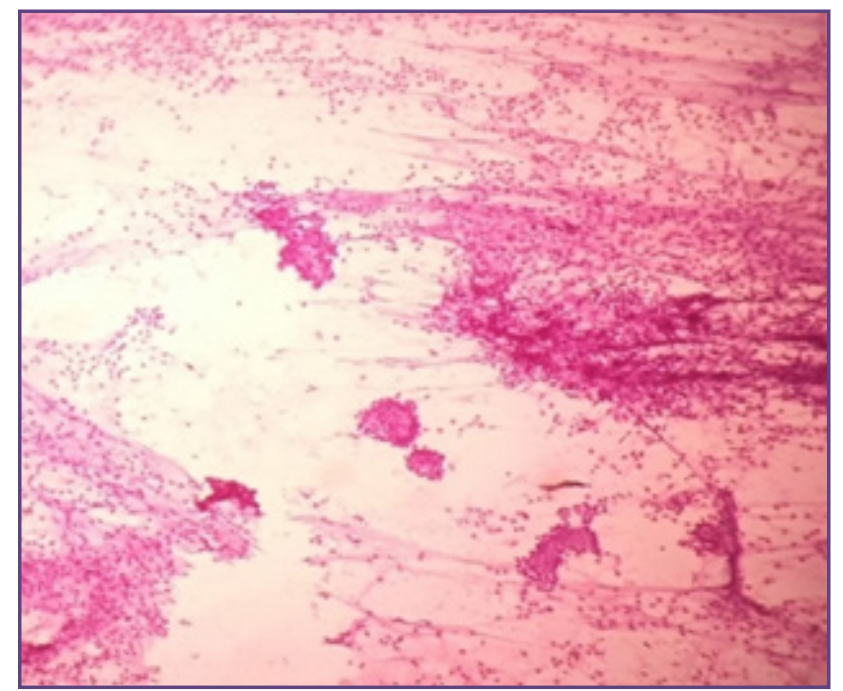

Fig. 4: cytology smear- Inflammatory breast lesionshowing benign cohesive ductal epithelial clusters in inflammatory background, H\& E stain, 100X.

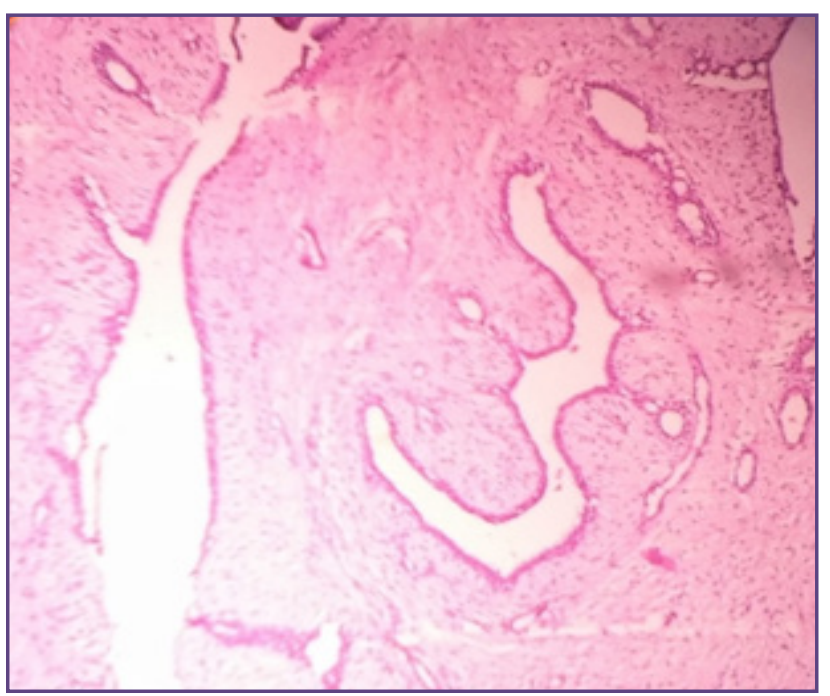

Fig. 6: Histology of Benign Phylloid Tumour, H \& E stain, 100x.

line pathological investigation in both screening and symptomatic populations. ${ }^{(5)}$

In present study, we observed that maximum number of benign lesions were found in $2^{\text {nd }}$ decade of life. Among these benign lesion, most common benign lesion was fibroadenoma. Similar findings have been observed by Ferguson et al. which shows commonest benign breast lesion is fibroadenoma occurring before age of 25 years. ${ }^{(8)}$

Assessing malignant breast lesions in present study, we observed that peak incidence of malignant breast lesion is in $5^{\text {th }}$ to $6^{\text {th }}$ decade of life. Similarly peak age of breast malignancies is 50.8 years in a study done by Murali and 
Cunden. ${ }^{(9)}$. In present study, we obtained that most frequent malignant lesion was invasive ductal carcinoma of Not Otherwise Specified type (IDC-NOS). Such findings are comparable with a study done by Sigh et al, in which they found ductal carcinoma was most frequently diagnosed breast malignancy. ${ }^{(10)}$

In present study, total 32 cases where FNAC smears were inadequate / unsatisfactory. That gave proportion of inadequate cases in present study was $10.5 \%$. This rate is higher than that obtained in a study done by Daramola et al. ${ }^{(1)}$ This propotion of undiagnosed cases on cytology can be reduced by immediate evaluation of cytology smear by pathologist using a rapid staining technique. This "onsite" evaluation makes FNAC even more cost effective modality and reducing chances of recalling patients for re-aspiration. ${ }^{(12)}$

Technical skills of a cytopahtologist performing FNAC are having very much influence of diagnostic yield. Unsatisfactory cytological smears can be due to insufficient experience of a pathologist, poor technique in performance of FNAC or due to the nature of lesion itself. Provision of adequate sample by an experienced pathologist can prove FNAC as highly reliable diagnostic tool. ${ }^{(13)}$

In present study, total two false negative cases were diagnosed. In one of that, we obtained heavily blood stained smears with mixed cytological features. Cytologically, this was diagnosed as a cystic lesion. On histological evaluation, it turned out to be an invasive ductal carcinoma of NOS type. Yeoh and Chan have also observed such pitfalls in cytodiagnosis. In their study, they got 6 false negative cases including 4 cases misdiagnosed as cystic lesions. ${ }^{(14)}$ Such type of 'missed diagnosis' on cytology can be obtained due to either heavily blood stained smear hindering cytological features or the smear contains mixed cytological findings.

Table 5 shows comparison of statistical data obtained in this study with the results obtained in those of other three study done by J Chavda, A. Daramola et al and N. Chauhan et al. ${ }^{(11,15,16)}$. The table shows the results obtained in this study is quite comparable regarding sensitivity, specificity and positive predictive values of FNAC as a diagnostic modality in detective malignant breast pathologies.

\section{Conclusion}

Palpable breast mass is one of the common presentation at surgical OPD. Chances of a breast lump being malignant are definitely present. So the proper evaluation of a breast lump is very essential part of patient management. FNAC of breast lump is now proved to be a rapid, reliable, cost effective diagnostic procedure with high degree patient compliance. Present study observed that the findings of breast FNACs are well correlated with histological diagnosis of respective breast lesions. This proves that cytodiagnosis by FNAC when in experienced hand are extremely useful in the evaluation of breast lumps.

Moreover, a benign diagnosis on FNA allows a time period in which a surgery can be planned or delayed, while a positive diagnosis of carcinoma on cytology allows preoperative discussion/ counselling of the patient and further planning of the therapy and reduces morbidity.

\section{Reference}

1. Globocan 2012 - Home [Internet]. [cited 2017 Jul 13]. Available from: http://globocan.iarc.fr/Default.aspx

2. Mitra S, Dey P. Fine-needle aspiration and core biopsy in the diagnosis of breast lesions: A comparison and review of the literature. Cytojournal. 2016;13:18.

3. Panjvani SI. Utility of Fine Needle Aspiration Cytology in the Evaluation of Breast Lesions. J Clin Diagnostic Res. 2013;2777-9.

4. Khan A, Jamali R, Jan M, Tasneem M. Correlation of Fine Needle Aspiration Cytology and Histopathology Diagnosis in the Evaluation of Breast Lumps. Int J Med Students. 2014;2(2):40-3.

5. Ahmed I, Nazir R, Chaudhary MY, Kundi S. Triple assessment of breast lump. J Coll Physicians Surg Pak. 2007 Sep;17(9):535-8.

6. Bukhari MH, Akhtar ZM. Comparison of accuracy of diagnostic modalities for evaluation of breast cancer with review of literature. Diagn Cytopathol. 2009 Jun $1 ; 37(6): 416-24$.

7. Goyal P, Sehgal S, Ghosh S, et al., "Histopathological Correlation of Atypical (C3) and Suspicious (C4) Categories in Fine Needle Aspiration Cytology of the Breast," International Journal of Breast Cancer, 2013, Article ID 965498, 5 pages, 2013. doi:10.1155/2013/965498.

8. Ferguson CM, Powell RW. Breast masses in young women. Arch Surg. 1989 Nov;124(11):1338-41.

9. Murali U, Cunden SM. Clinico-pathological Correlation of Breast lumps in Mauritian women. IOSR J Dent Med Sci Ver I. 2015;14(7):2279-861.

10. Singh P, Chaudhry M, Nauhria S, Rao D. Cytomorphological patterns of breast lesions diagnosed on fine-needle aspiration cytology in a tertiary care hospital. Int J Med Sci Public Heal Int J Med Sci Public Heal Online. 2015;4(5).

11. Daramola AO, Odubanjo MO, Obiajulu FJ, Ikeri NZ, Banjo AAF. Correlation between Fine-Needle Aspiration Cytology 
and Histology for Palpable Breast Masses in a Nigerian Tertiary Health Institution. Int J Breast Cancer. 2015;2015.

12. Nasuti JF, Gupta PK, Baloch ZW. Diagnostic value and costeffectiveness of on-site evaluation of fine-needle aspiration specimens: Review of 5,688 cases. Diagn Cytopathol. 2002 Jul;27(1):1-4.

13. Anderson L, Melamed MR. Koss' apostrophe, Diagnostic Cytology and Its Histopathologic Bases. Pathology. 2006 Apr 1;38(2):193.
14. Yeoh GP, Chan KW. Fine needle aspiration of breast masses: an analysis of 1533 cases in private practice. Hong Kong Med J. 1998;4(3):283-8.

15. Srilakshmi HP, Chavda J. A Study Of Cyto-Histological Correlation Of Breast Lesions. 2013;4(September 2010):54-6.

16. Chauhan N, Pathak VP, Saini S, Singh Gaur D. Indian Medical Gazette Cytohistopathological Correlation in Palpable Breast Lesions. 2012;

*Corresponding author:

Dr. Sheetal Kher, Dept of Pathology Gotri Medical College, Vadodara, Gujarat 390021, India

Phone: +91 02652398008

Email: drsheetalkher@gmail.com

Date of Submission : 02.03.2017

Date of Acceptance : 06.08.2017

Financial or other Competing Interests: None.
Date of Publication : 11.12.2017 